\title{
Mild riboflavin deficiency is highly prevalent in school-age children but does not increase risk for anaemia in Côte d'Ivoire
}

\author{
Fabian Rohner ${ }^{1}$, Michael B. Zimmermann ${ }^{1}$, Rita Wegmueller ${ }^{1}$, Andreas B. Tschannen ${ }^{2}$ \\ and Richard F. Hurrell ${ }^{1}$ \\ ${ }^{1}$ Human Nutrition Laboratory, Institute of Food Science and Nutrition, ETH Zurich, Schmelzbergstrasse 7, 8092 Zürich, \\ Switzerland \\ ${ }^{2}$ Centre Suisse de Recherches Scientifiques (CSRS), 01 BP 1303, Abidjan 01, Côte d'Ivoire
}

(Received 12 June 2006 - Revised 20 November 2006 - Accepted 20 November 2006)

\begin{abstract}
There are few data on the prevalence of riboflavin deficiency in sub-Saharan Africa, and it remains unclear whether riboflavin status influences the risk for anaemia. The aims of this study were to: (1) measure the prevalence of riboflavin deficiency in children in south-central Côte d'Ivoire; (2) estimate the riboflavin content of the local diet; and (3) determine if riboflavin deficiency predicts anaemia and/or iron deficiency. In 5- to 15-year-old children ( $n$ 281), height, weight, haemoglobin (Hb), whole blood zinc protoporphyrin (ZPP), erythrocyte glutathione reductase activity coefficient (EGRAC), serum retinol, C-reactive protein (CRP) and prevalence of Plasmodium spp. (asymptomatic malaria) and Schistosoma haematobium (bilharziosis) infections were measured. Three-day weighed food records were kept in twenty-four households. Prevalence of anaemia in the sample was 52\%; $59 \%$ were iron-deficient based on an elevated ZPP concentration, and 36\% suffered from iron deficiency anaemia. Plasmodium parasitaemia was found in $49 \%$ of the children. Nineteen percent of the children were infected with S. haematobium. Median riboflavin intake in 5- to 15 -year-old children from the food records was $0.42 \mathrm{mg} / \mathrm{d}, \sim 47 \%$ of the estimated average requirement for this age group. Prevalence of riboflavin deficiency was $65 \%$, as defined by an EGRAC value $>1 \cdot 2$. Age, elevated CRP and iron deficiency were significant predictors of $\mathrm{Hb}$. Riboflavin-deficient children free of malaria were more likely to be iron deficient (odds ratio; 3.07; 95\% CI 1.12, 8.41). In conclusion, nearly two-thirds of school-age children in south-central Côte d'Ivoire are mildly riboflavin deficient. Riboflavin deficiency did not predict $\mathrm{Hb}$ and/or anaemia, but did predict iron deficiency among children free of malaria.
\end{abstract}

Riboflavin: Iron: Deficiency: Children: Anaemia: Côte d'Ivoire

Riboflavin (vitamin $\mathrm{B}_{2}$ ) is required for many metabolic pathways, usually as a precursor of the flavin coenzyme, NAD, in redox reactions (McCormick, 1997). Riboflavin deficiency is particularly common in regions where intakes of dairy products and meat are low (Neumann et al. 2003). Deficiency causes impaired growth, cheilosis, angular stomatitis, glossitis, dermatitis and impaired vision (Venkataswamy, 1967; Batey et al. 1992; FAO/WHO, 2001). Schoolchildren, in both developing and industrialised countries, are an age group at high risk for riboflavin deficiency (Powers, 2003).

In Western Africa, anaemia affects $50-80 \%$ of the children (ACC/SCN, 2000; WHO/UNICEF/UNU, 2001). There are many aetiologies of anaemia in African children. These include malaria, blood loss from parasitic infections, vitamin A deficiency and diets low in bioavailable iron (ACC/SCN, 2000). Riboflavin deficiency may also impair erythropoiesis and contribute to anaemia (Foy \& Kondi, 1953; Foy et al. 1964). Suggested mechanisms for this effect of riboflavin deficiency are decreased mobilisation of iron from stores (Sirivech et al. 1974; Powers, 1995), decreased iron absorption and increased iron losses (Adelekan \& Thurnham, 1986; Powers et al. 1988; Butler \& Topham, 1993). Whereas these mechanisms have been investigated in animals, there are few data from human studies. Riboflavin supplements given concurrently with iron improve the response to iron supplementation in pregnant and lactating women, adult males and schoolchildren (Buzina et al. 1979; Charoenlarp et al. 1980; Ajayi et al. 1990). A stable isotope study in adult Gambian men showed a greater increase in $\mathrm{Hb}$ values with riboflavin supplementation compared with controls (both groups received iron supplements), but failed to demonstrate an increase in iron absorption, suggesting that the improvement in $\mathrm{Hb}$ may have been due to iron mobilisation from stores (Fairweather-Tait et al. 1992).

The aims of the present study were to: (1) determine the prevalence of riboflavin deficiency in school-age children in southern Côte d'Ivoire; (2) estimate the riboflavin content of the local diet; and (3) investigate if riboflavin status contributes to anaemia or iron deficiency in this population.

\footnotetext{
Abbreviations: CRP, C-reactive protein; EGRAC, erythrocyte glutathione reductase activity coefficient; SR, serum retinol; ZPP, zinc protoporphyrin.

* Corresponding author: Fabian Rohner, fax, +41(44)632 14 70, email fabian.rohner@ilw.agrl.ethz.ch
} 


\section{Subjects and methods}

Study site

The study sites were two villages in Côte d'Ivoire from geographically distinct regions. Orbaff is a rural village in the Dabou district of Côte d'Ivoire, $10 \mathrm{~km}$ from the southern coast. The climate is tropical, with a temperature of $\geq 27^{\circ} \mathrm{C}$ and a relative humidity of $\geq 80 \%$ much of the year. Plantain, rice, yam and dried, smoked fish are eaten regularly. Bringakro is further north (District Toumodi), about $180 \mathrm{~km}$ northwest of Abidjan. The region is situated in the transition zone from rainforest to savannah, with a mean temperature of $27^{\circ} \mathrm{C}$ and a relative humidity of $70 \%$. Staple foods in this area are yam, plantain, cassava and red palm oil. The surveys were conducted in May 2004 in Orbaff (Wegmuller et al. 2006), and in May 2005 in Bringakro.

\section{Subjects and enrolment}

In both villages, a random sample was taken from children attending grades $1-5$ in primary schools, with 50 and $28 \%$ of children in these grades enrolled in Bringakro and Orbaff, respectively. Informed written consent was obtained from the school directors and the parents of the children. The Ethical Committee of the Swiss Federal Institute of Technology in Zürich, Switzerland, and the Scientific Council of the CSRS in Abidjan, Côte d'Ivoire gave ethical approval for the study. A total sample size of 280 children was calculated assuming a change in $\mathrm{Hb}$ of $3 \mathrm{~g} / \mathrm{l}$ as clinically relevant, a standard deviation (SD) of $\mathrm{Hb}$ of $12 \mathrm{~g} / \mathrm{l}$, a significance level of $95 \%$, and a power of $75 \%$ for a two-sided outcome.

\section{Screening}

Weight and height were measured upon registration (surname, first name, sex, date of birth) of the child. For these measurements, children removed their shoes and wore light clothing. Weight was recorded to the nearest $0.1 \mathrm{~kg}$ (Skyline, Soehnle-Waagen GmbH \& Co. KG, Murrhardt, Germany), and height to the nearest $0.5 \mathrm{~cm}$ (Person check $^{\circledR}$, KaWe, Asperg, Germany) by the local nurse and an experienced technician. Age was obtained from the school registers, where age is taken from birth certificates. Venous blood samples $(7.5 \mathrm{ml})$ were drawn in the morning into EDTA-treated evacuated tubes, and blood samples were kept in the dark on ice during transport to a nearby laboratory. A morning casual spot urine sample was collected for measurement of microhaematuria (as an indicator for bilharziosis). After the screening, children with iron deficiency were given supplemental oral iron for 12 weeks (daily $60 \mathrm{mg}$ of iron as $\mathrm{FeSO}_{4}$ ), and children with bilharziosis were given a single dose of praziquantel $(40 \mathrm{mg} / \mathrm{kg})$.

\section{Dietary assessment}

Three-day weighed food records were collected in Orbaff in 24 randomly selected households. The records were done on three consecutive days (including two weekdays and one weekend day). In the village, family meals are traditionally eaten from shared bowls, but to estimate individual food intake during the 3 days of recording, families ate from individual bowls. Edible portions of all food and beverages were weighed using a Soehnle scale (Vera 67002, Soehnle-Waagen GmbH \& Co. KG, Murrhardt, Germany) accurate to $\pm 1 \mathrm{~g}$ during preparation and consumption. Meals typically consisted of a cooked staple and a sauce. When the meal was ready, the total weight of the cooked staple and sauce was weighed. After the meal, the food that remained uneaten was weighed and the proportion of staple to sauce was estimated by a team of experienced investigators. Subjects absent during the day were asked about their food intake and amounts eaten outside the home; these estimations were then added to the food records. Riboflavin intake was calculated using food composition tables (Toury et al. 1965; FAO, 1968; Bundesinstitut für gesundheitlichen Verbraucherschutz und Veterinärmedizin, 1996) and food analysis software EBISpro (University of Hohenheim/Stuttgart, Germany).

\section{Laboratory analysis}

In Orbaff, $\mathrm{Hb}$ measurement was performed on the day of blood sampling on an AcT8 Counter (Beckman Coulter, Krefeld, Germany) using three-level controls provided by the manufacturer. In Bringakro, because the AcT8 Counter was not available, the Hemocue system was used (Hemocue, Angelsborg, Sweden) using two-level controls provided by the manufacturer. Venous blood was used for both methods; values obtained by these two $\mathrm{Hb}$ methods from venous blood are highly correlated (Morris et al. 2001). Zinc protoporphyrin (ZPP) was measured on washed red blood cells within $7 \mathrm{~d}$ of blood sampling in duplicate with a haematofluorometer (Aviv Biomedical, Lakewood, NJ, USA) (Hastka et al. 1992), with standards provided by the manufacturer. C-reactive protein (CRP) in samples from Bringakro was measured using an automated chemiluminescent high sensitivity immunoassay system (IMMULITE ${ }^{\circledR}$, Diagnostic Products Corporation, Los Angeles, CA, USA), and Orbaff CRP samples were measured using nephelometry (TURBOX ${ }^{\circledR}$, Orion Diagnostics, Espoo, Finland). Anaemia was defined as $\mathrm{Hb}<120 \mathrm{~g} / \mathrm{l}$ in children aged $\geq 12$ years, and $\mathrm{Hb}<115 \mathrm{~g} / \mathrm{l}$ in children aged 5-12 years (WHO/UNICEF/UNU, 2001). Iron deficiency was defined by a ZPP value $>40 \mu \mathrm{mol} / \mathrm{mol}$ haem (Hastka et al. 1992). CRP values $<10 \mathrm{mg} / \mathrm{l}$ were defined as normal (Pepys, 1981). Serum retinol (SR) was measured by HPLC (Merck-Hitachi, Tokyo, Japan) according to Tanumihardjo et al. (2004) with reference material from the National Institute of Standards and Technology (Gaithersburg, MD, USA); vitamin A deficiency was defined as an SR $<0.70 \mu \mathrm{mol} /$, and low vitamin A status as an SR $<1.05 \mu \mathrm{mol} / \mathrm{l}$ (WHO, 1996). Riboflavin was measured by the erythrocyte glutathione reductase activity coefficient (EGRAC) assay using a modification of the method of Dror et al. (1994). In our laboratory, the inter- and intra-assay $\mathrm{CV}$ of the EGRAC method is 3 and $4 \%$, respectively. Although there is no consensus for EGRAC cut-off values for riboflavin deficiency (Tillotson \& Baker, 1972; Prasad et al. 1992; Sauberlich, 1999), we used cut-offs specified for this EGRAC assay (Dror et al. 1994), i.e. values $>1.2$ indicated marginal deficiency and values $>1.4$ indicated clear deficiency (Sauberlich, 1999). For statistical analysis, EGRAC values $>1.2$ were used. On the day of blood sampling, whole blood was used to prepare a thick and a thin smear for malaria parasites by the 
Giemsa coloration technique (WHO, 1990). Parasites were counted against leucocytes; fields containing $>200$ leucocytes were counted and if $<10$ parasites were identified, the counting continued up to 500 leucocytes. These counts were converted to the number of parasites per $\mu$ l of blood, assuming a leucocyte count of $8000 / \mu l$ (WHO, 1990). On the day of blood sampling, haematuria, as an indirect marker for infection with Schistosoma haematobium, was assessed semiquantitatively by dipstick (Combur 7, Roche Diagnostics GmbH, Mannheim, Germany).

\section{Statistical analysis}

Data processing and statistical analysis were done using Excel (XP 2002; Microsoft, Redmond, CA, USA) and SPSS 13.0 (SPSS Inc., Chicago, IL, USA). Height-for-age and weightfor-age Z-scores were calculated using Epi-Info (Epi-Info Version 3.3.2, Centers for Disease Control and Prevention, Atlanta, GA, USA). All data except ZPP were normally distributed and are presented as means and their SD. ZPP data were skewed and are presented as medians (ranges); for statistical analysis, these values were log-transformed. One-way ANOVA was used to test for differences for all scaled variables among the different geographic areas; the Mann-Whitney test was applied for ordinal data. Two-tailed Pearson's correlation coefficients were used to examine the relationship between iron status or anaemia and riboflavin status, malaria, inflammation, SR and haematuria. Stepwise linear regression on $\mathrm{Hb}$ and $\log \mathrm{ZPP}$ was performed with age, sex, EGRAC, $\mathrm{SR}, \mathrm{CRP}$, malaria and $\mathrm{Hb}$ or $\log \mathrm{ZPP}$ as independent variables. Odds ratios for the risk of anaemia or iron deficiency in riboflavin deficiency were calculated. $P$ values $<0.05$ were considered statistically significant.

\section{Results}

Three-day weighed food records

The $3 \mathrm{~d}$ weighed food records were kept in 24 families comprising 207 subjects (median age: 16 years; range: 2-81 years); the results for children $6-15$ years of age $(n 71)$ are reported here. Daily intakes of riboflavin ranged from $0 \cdot 17$ to $1.16 \mathrm{mg}$, with a median of $0.42 \mathrm{mg}$, representing 70 and $47 \%$ of the estimated average requirement for children 6-8 years of age and those aged 9-13, respectively (Institute of Medicine, 2001). Riboflavin intake was low due to infrequent consumption of animal foods, with the exception of smoked fish, and the negligible riboflavin content of cassava, the dietary staple. Median (range) iron intake was $9.8 \mathrm{mg}$ (3.6-19.8) $\mathrm{mg} / \mathrm{d}$, well above the estimated average requirement of $6.3 \mathrm{mg} / \mathrm{d}$ for 6 - to 15 -year-old children. Only $21 \%$ of children had iron intakes below the estimated average requirement. However, the bioavailability of the dietary iron was probably low, as $90 \%$ of iron was non-haem iron.

\section{Anthropometry}

Mean age of the screened children was $10 \cdot 2$ (SD 2.3) years, mean weight and height were 31.8 (SD 10.1) $\mathrm{kg}$ and 1.38 (SD $0 \cdot 15) \mathrm{m}$, respectively. Forty-four percent of the children were female. As shown in Table 1, the children from the two villages differed significantly in sex ratio, age, weight and height. However, height-for-age as well as weight-forage $Z$-scores were not significantly different. Eight percent of the children were stunted (height-for-age $Z$-score less than $-2 \mathrm{SD}$ ) and $11 \%$ were undernourished (weight-for-age $Z$-score less than $-2 \mathrm{SD}$ ).

\section{Prevalence of anaemia, iron deficiency and iron deficiency anaemia}

A high prevalence of anaemia (52\%) was found in the studied population (Table 1). Nearly $60 \%$ of all children had iron deficiency, and iron deficiency was present in $69 \%$ of the anaemic children. Iron deficiency anaemia was present in $36 \%$ of all children. As expected, ZPP and $\mathrm{Hb}$ were significantly correlated (Table 2), but no other parameter alone influenced these two variables. Vitamin A deficiency is thought to contribute to anaemia (Reddy, 1998), but only $2 \%$ of the children in the sample were vitamin A deficient. Comparing riboflavindeficient ( $n$ 182) and riboflavin-sufficient ( $n$ 99) children, ZPP concentrations were $51(17-296)$ and 46 (20-49) $\mu \mathrm{mol} / \mathrm{mol}$ haem, the prevalence of iron deficiency was 63.2 and $52.5 \%$, and the prevalence of iron deficiency anaemia was 35.7 and $36.4 \%$, respectively.

\section{Prevalence of malaria parasites and microhaematuria}

Despite a high prevalence of malaria parasites (49\%), the severity of infestation was low, with only $8 \%$ of the children having a parasite load $>1000 / \mu$ l blood, and only two children having clinical malaria, as defined as a parasite load $>5000$ / $\mu l$ blood (Trape, 1985). Plasmodium load was positively correlated with SR, but with no other variable (Table 2). Microhaematuria, an indicator for $S$. haematobium infection, was present in $19 \%$ of the children.

\section{Prevalence of inflammation}

The prevalence of inflammation or infection, as indicated by elevated CRP concentrations, was moderate in both villages. Only about $15 \%$ of the children had an elevated CRP despite a considerably higher prevalence of Plasmodium parasitaemia. This discrepancy may at least partly be explained by the generally low malaria severity.

\section{Prevalence of riboflavin deficiency}

Two-thirds of the children suffered from riboflavin deficiency, but the degree of deficiency was mild. Only $2 \%$ of children had EGRAC values $>1.4$, suggesting clear deficiency. Of the riboflavin-deficient children, $7.5 \%$ showed EGRAC values $>1.4$. EGRAC was not correlated with any other measured variable (Table 2).

\section{Regression analysis and odds ratios}

In the stepwise linear regression on $\mathrm{Hb}$, age $(P<0 \cdot 001), \log$ ZPP $(P<0.001)$ and CRP $(P<0.05)$ were significant predictors. With $\log \mathrm{ZPP}$ as the dependent variable, $\mathrm{Hb}(P<0.001)$ and EGRAC $(P<0.05)$ were significant predictors. Overall, correlations were modest. 
Table 1. Anthropometric, nutritional and health characteristics of Ivorian children in two villages of Côte d'Ivoire: Orbaff, in the southern tropical zone, and Bringakro, in the savannah transition zone

\begin{tabular}{|c|c|c|c|c|c|c|}
\hline & The two villages ( $n$ 281) & & Orbaff $(n 171)$ & & Bringakro (n 110) & \\
\hline Age $^{*}$ (years) $\dagger$ & $10 \cdot 2$ & $2 \cdot 3$ & $9 \cdot 9$ & $2 \cdot 3$ & $10 \cdot 8$ & $2 \cdot 2$ \\
\hline Height $^{*}(m) t$ & 1.38 & 0.15 & 1.37 & $0 \cdot 14$ & 1.41 & 0.17 \\
\hline Weight $^{*}(\mathrm{~kg}) \dagger$ & 31.8 & $10 \cdot 1$ & 30.4 & 8.7 & 33.9 & 11.6 \\
\hline Height-for-age Z-scores & -0.3 & & -0.2 & & -0.4 & \\
\hline $\begin{array}{l}\text { Prevalence of stunted children, less than } \\
\quad-\text { SD }(n(\%))\end{array}$ & $23(8)$ & & $14(8)$ & & $9(9)$ & \\
\hline Weight-for-age $Z$-scores & -0.6 & & -0.6 & & -0.7 & \\
\hline $\begin{array}{l}\text { Prevalence of undernourished children, less than } \\
- \text { SD }(n(\%))\end{array}$ & $27(10)$ & & $15(9)$ & & $12(11)$ & \\
\hline Sex ratio (female:male) $†$ & 0.8 & & 0.7 & & 1.0 & \\
\hline $\mathrm{Hb}(\mathrm{g} / \mathrm{l})^{*}$ & 116 & 12 & 117 & 12 & 115 & 12 \\
\hline Zinc protoporphyrin $(\mu \mathrm{mol} / \mathrm{mol}$ haem $) \dagger \ddagger$ & $49.5(17-296)$ & & $53.0(24-296)$ & & $45 \cdot 2(17-288.5)$ & \\
\hline Prevalence of anaemia $(n(\%))$ & & $145(52)$ & $83(48)$ & & $62(56)$ & \\
\hline Prevalence of iron deficiency anaemia $(n(\%))$ & $101(36)$ & & $61(36)$ & & $40(36)$ & \\
\hline $\begin{array}{l}\text { Prevalence of iron deficiency without anaemia } \\
(n(\%))\end{array}$ & $167(59)$ & & $112(66)$ & & $55(50)$ & \\
\hline Serum retinol $(\mu \mathrm{mol} / \mathrm{l})^{*}$ & $1.25 \S$ & 0.32 & $1 \cdot 30 \|$ & 0.2 & $1 \cdot 22$ & 0.319 \\
\hline Prevalence of vitamin A deficiency $(n(\%))$ & $2(1)$ & & $0(0)$ & & $2(2)$ & \\
\hline Riboflavin EGRAC* & 1.25 & 0.12 & 1.26 & $0 \cdot 12$ & 1.24 & 0.11 \\
\hline Prevalence of EGRAC $>1.2(n(\%))$ & $182(65)$ & & $109(64)$ & & $73(66)$ & \\
\hline Prevalence of Plasmodium parasitaemia $(n(\%))$ & $78(49)^{\star \star}$ & $27(55) \dagger \dagger$ & $51(46)$ & & & \\
\hline Prevalence of microhaematuria $(n(\%)) \dagger^{\star \star}$ & $31(19) \ddagger \ddagger$ & & 2 (3)§§ & & $29(26)$ & \\
\hline Prevalence of elevated CRP $(n(\%))$ & $43(15)$ & & $23(13)$ & & $20(18)$ & \\
\hline
\end{tabular}

EGRAC, erythrocyte glutathione reductase activity coefficient; CRP, C-reactive protein.

${ }^{*}$ Mean and standard deviation.

† Schools differ significantly by ANOVA $(P<0.05)$.

$\ddagger$ Median (range).

$\S n 162$.

$\| n 55$.

I $n 107$.

${ }^{* *} n 159$.

十† $n$ 49.

拉 $n 161$

$\S \S n 51$.

In riboflavin-deficient subjects, the odds ratios $(95 \% \mathrm{CI})$ for anaemia and iron deficiency were $0.69(0.42,1.13)$ and $1.55(0.94,2 \cdot 55)$, respectively. Because EGRAC values may be influenced by malaria (see below), odds ratios were also calculated after excluding subjects with malaria. In riboflavin-deficient subjects (EGRAC $>1.2$ ) without Plasmodium infection $(n 80)$, the odds ratio for iron deficiency was significant $(3.07 ; 1 \cdot 12,8.41)$.

\section{Discussion}

Mild riboflavin deficiency was very common in the study children, with nearly two-thirds of the children affected. A previous
Ivorian study reported EGRAC values $>1 \cdot 68$, but no information on the age of the subjects or the prevalence of riboflavin deficiency was provided (Arnaud et al. 2001). A food survey in central Côte d'Ivoire found low consumption of dairy products and meat, the usual major dietary sources of riboflavin, but riboflavin intakes were not reported (Staubli-Asobayire, 2000). Although there are few data on the riboflavin status of children in sub-Saharan Africa, the few published studies suggest that riboflavin deficiency may be common. A study in Botswana reported that $33-40 \%$ of the examined children had an EGRAC $\geq 1.4$ (Abrams et al. 2003). In Kenya, approximately one-third of the children were riboflavin deficient, measured as red blood cell riboflavin (Siekmann et al. 2003). In 2- to

Table 2. Pearson's correlation coefficients between nutrition and health-related variables in schoolaged children in two villages of Côte d'lvoire

\begin{tabular}{lcccccc}
\hline & ZPP & CRP & EGRAC & Malaria & Schistosoma & SR \\
\hline Hb & $-0.175^{*}$ & -0.062 & 0.112 & -0.010 & 0.060 & 0.093 \\
ZPP & - & 0.037 & 0.054 & 0.041 & -0.117 & 0.055 \\
CRP & - & - & -0.018 & -0.041 & 0.066 & $-0.164 \dagger$ \\
EGRAC & - & - & - & 0.043 & -0.110 & 0.022 \\
Malaria & - & - & - & - & -0.045 & $0.214 \dagger$ \\
Schistosoma & - & - & - & - & - & -0.003 \\
\hline
\end{tabular}

ZPP, zinc protoporphyrin; CRP, C-reactive protein; EGRAC, erythrocyte glutathione reductase activity coefficient; SR, serum retinol.

${ }^{*}$ Correlation is significant at the 0.05 level.

†Correlation is significant at the 0.01 level. 
5-year-old South African children, intakes of riboflavin were only $49 \%$ of the RDA (Faber et al. 2001).

In this study, although malaria was endemic, with $49 \%$ of the children infected, the parasite load was generally low. This prevalence is similar to that reported in a previous Ivorian study, but the severity of infection was higher in that study (Staubli Asobayire et al. 2001). A study conducted in eastern Côte d'Ivoire found that malaria affected $74-86 \%$ of 7 - to 11 -year-old children and $68 \%$ of children $>12$ years old (Girardin et al. 2004). Microhaematuria as an indicator of $S$. haematobium infection varied markedly between villages, with nearly one-third of the children affected in Bringakro. This high prevalence of $S$. haematobium infection is consistent with a previous report from this region of Côte d'Ivoire, where $24.6 \%$ of the children had microhaematuria, although data varied markedly depending on the nearby presence of standing water (N'Goran et al. 1998). Anaemia prevalence in the present study $(52 \%)$ was similar to that found in an earlier report in Ivorian children (46\%) (Staubli Asobayire et al. 2001). However, in that study, the prevalence of elevated ZPP levels was higher $(83 \%)$ than in the present study $(59 \%)$.

There are several limitations to this study. First, the use of a single measure of iron status (ZPP) probably reduced our ability to define iron deficiency accurately (Zimmermann et al. 2005). Previous studies have suggested that ZPP may be elevated by infection and/or inflammation, and thus iron deficiency using ZPP may be overestimated in areas of endemic infection (Staubli Asobayire et al. 2001). However, in the present study, there was no correlation between ZPP and CRP, presence of malaria or suspected schistosomiasis. It has been suggested that acute malaria may spuriously elevate EGRAC (Anderson et al. 1994; Traunmuller et al. 2003). However, acute malaria was rare in our study population, and there was no relationship between EGRAC and malaria, so our estimate of riboflavin deficiency based on EGRAC is likely to be valid.

The public health impact of widespread riboflavin deficiency in schoolchildren is unclear; but it may influence iron metabolism (Sirivech et al. 1974; Adelekan \& Thurnham, 1986; Powers et al. 1988; Butler \& Topham, 1993; Powers, 1995). In our sample, anaemia and iron deficiency were common, with prevalences $>50 \%$, and two-thirds of the anaemic children were iron deficient. Neither linear regression nor calculation of relative risk identified riboflavin deficiency as a significant predictor of $\mathrm{Hb}$ or anaemia. Thus, our data do not support a detrimental effect of riboflavin deficiency on anaemia, as suggested by earlier studies (Foy \& Kondi, 1953, 1958), a finding that might be explained by the low severity of the riboflavin deficiency in our sample. However, the risk of iron deficiency was increased 3-fold in children with riboflavin deficiency and without malaria. There are two likely explanations for this association. First, poor overall quality of the diet may have led to multiple micronutrient deficiencies; however, there was a very low prevalence of vitamin A deficiency, and iodine status appeared to be adequate. Secondly, the results could reflect impairment of iron absorption and/or metabolism by riboflavin deficiency, as suggested by earlier studies (Powers et al. 1988; Butler \& Topham, 1993; Powers, 1995). In three trials in children and pregnant women (Charoenlarp et al. 1980; Powers et al. 1983; Suprapto et al. 2002), riboflavin and iron supplementation produced a greater increase in $\mathrm{Hb}$ compared with iron supplements given alone, although the results may have been confounded by concomitant folic acid supplementation in two (Charoenlarp et al. 1980; Suprapto et al. 2002). In contrast, another trial reported no additional benefit of riboflavin plus iron compared with iron supplementation alone in young adults (Powers \& Bates, 1987). A study in a small number of pregnant women reported that riboflavin supplementation alone or in combination with iron supplementation did not prevent a decrease in $\mathrm{Hb}$, although the decrease was less in the treated group than in the control group (Powers et al. 1985). Similarly, no effect could be found in a riboflavin supplementation trial in Croatian schoolchildren with adequate $\mathrm{Hb}$ levels (Suboticanec et al. 1990). Taken together, these data suggest that the effect of riboflavin status on $\mathrm{Hb}$ is variable, and may be confounded by the multifactorial aetiology of anaemia, particularly in countries in sub-Saharan Africa.

In conclusion, there is a high prevalence of mild riboflavin deficiency in Ivorian schoolchildren, but severe deficiency was rare. Riboflavin deficiency was associated with iron deficiency in children free of malaria parasites. However, there was no significant association between riboflavin status and anaemia.

\section{Acknowledgements}

We thank the participating children, school directors and teachers, and we thank the authorities of the villages and health districts. We are grateful for the assistance of JeanPaul Gnanzou, Yao Edouard Koffi from the Institut National de Santé Publique; Traoré Mahamadou and Kigbafori Silué from the Centre Suisse de Recherches Scientifiques; and Christophe Zeder, Renata Wälchli, Valeria Galetti and Ralf Biebinger from ETH Zurich. We thank Dr Paul Lohmann GmbH KG (Emmerthal, Germany) who supplied the iron sulphate tablets. We thank Luciano Molinari from the Children's Hospital in Zurich for support in statistical analysis. Financial support for the study was from the ETH through a private donation. None of the authors has financial or personal conflicts of interest with regard to this study.

\section{References}

Abrams SA, Mushi A, Hilmers DC, Griffin IJ, Davila P \& Allen L (2003) A multinutrient-fortified beverage enhances the nutritional status of children in Botswana. J Nutr 133, 1834-1840.

ACC/SCN (2000) Fourth Report on the World Nutrition Situation. Geneva: UN ACC/SCN in collaboration with IFPRI.

Adelekan DA \& Thurnham DI (1986) The influence of riboflavin deficiency on absorption and liver storage of iron in the growing rat. $B r J$ Nutr 56, 171-179.

Ajayi OA, Okike OC \& Yusuf Y (1990) Haematological response to supplements of riboflavin and ascorbic acid in Nigerian young adults. Eur J Haematol 44, 209-212.

Anderson BB, Scattoni M, Perry GM, Galvan P, Giuberti M, Buonocore G \& Vullo C (1994) Is the flavin-deficient red blood cell common in Maremma, Italy, an important defense against malaria in this area? Am J Hum Genet 55, 975-980.

Arnaud J, Malvy D, Richard MJ, Faure H \& Chaventre A (2001) Selenium status in an iodine deficient population of the West Ivory Coast. J Physiol Anthropol Appl Hum Sci 20, 81-84. 
Batey DW, Daneshgar KK \& Eckhert CD (1992) Flavin levels in the rat retina. Exp Eye Res 54, 605-609.

Bundesinstitut für gesundheitlichen Verbraucherschutz und Veterinärmedizin (1996) Bundeslebensmittelschlüssel. Berlin.

Butler BF \& Topham RW (1993) Comparison of changes in the uptake and mucosal processing of iron in riboflavin-deficient rats. Biochem Mol Biol Int 30, 53-61.

Buzina R, Jusic M, Milanovic N, Sapunar J \& Brubacher G (1979) The effects of riboflavin administration on iron metabolism parameters in a school-going population. Int J Vitam Nutr Res 49, 136-143.

Charoenlarp P, Pholpothi T, Chatpunyaporn P \& Schelp FP (1980) The effect of riboflavin on the hematologic changes in iron supplementation of schoolchildren. Southeast Asian J Trop Med Public Health 11, 97-103.

Dror Y, Stern F \& Komarnitsky M (1994) Optimal and stable conditions for the determination of erythrocyte glutathione reductase activation coefficient to evaluate riboflavin status. Int $J$ Vitam Nutr Res 64, 257-262.

Faber M, Jogessar VB \& Benade AJ (2001) Nutritional status and dietary intakes of children aged 2-5 years and their caregivers in a rural South African community. Int J Food Sci Nutr 52, 401-411.

Fairweather-Tait SJ, Powers HJ, Minski MJ, Whitehead J \& Downes R (1992) Riboflavin deficiency and iron absorption in adult Gambian men. Ann Nutr Metab 36, 34-40.

FAO (1968) Food Composition Table for Use in Africa. Rome: Food and Agriculture Organization.

FAO/WHO (2001) Thiamin, riboflavin, niacin, vitamin $\mathrm{B}_{6}$, pantothenic acid and biotin. In Human Vitamin and Mineral Requirements, pp. 27-51. Rome: FAO.

Foy H \& Kondi A (1953) A case of true red cell aplastic anaemia successfully treated with riboflavin. J Pathol Bacteriol 65, 559-564.

Foy H \& Kondi A (1958) Anaemias of the Tropics: East Africa; with special reference to proteins and liver damage. Trans $R$ Soc Trop Med Hyg 52, 46-70.

Foy H, Kondi A \& Mbaya V (1964) Effect of riboflavine deficiency on bone marrow function and protein metabolism in baboons. Preliminary report. Br J Nutr 18, 307-318.

Girardin O, Dao D, Koudou BG, et al. (2004) Opportunities and limiting factors of intensive vegetable farming in malaria endemic Cote d'Ivoire. Acta Trop 89, 109-123.

Hastka J, Lasserre JJ, Schwarzbeck A, Strauch M \& Hehlmann R (1992) Washing erythrocytes to remove interferents in measurements of zinc protoporphyrin by front-face hematofluorometry. Clin Chem 38, 2184-2189.

Institute of Medicine (2001) Dietary Reference Intakes for Vitamin A, Vitamin K, Arsenic, Boron, Chromium, Copper, Iodine, Iron, Manganese, Molybdenum, Nickel, Silicon, Vanadium, and Zinc. Washington, DC: National Academy Press.

McCormick DB (1997) Co-enzymes, biochemistry. In Encyclopedia of Human Biology, pp. 847-864 [R Dulbecco, editor]. San Diego: Academic Press.

Morris LD, Pont A \& Lewis SM (2001) Use of a new HemoCue system for measuring haemoglobin at low concentrations. Clin Lab Haematol 23, 91-96.

N'Goran EK, Utzinger J, Traore M, Lengeler C \& Tanner M (1998) [Use of a questionnaire for quick identification of the principal foci of urinary bilharziasis in central Ivory Coast]. Med Trop (Mars) 58, 253-260.

Neumann CG, Bwibo NO, Murphy SP, Sigman M, Whaley S, Allen LH, Guthrie D, Weiss RE \& Demment MW (2003) Animal source foods improve dietary quality, micronutrient status, growth and cognitive function in Kenyan school children: background, study design and baseline findings. J Nutr 133, 3941S-3949S.

Pepys MB (1981) C-reactive protein fifty years on. Lancet 1, $653-657$.

Powers HJ (1995) Riboflavin-iron interactions with particular emphasis on the gastrointestinal tract. Proc Nutr Soc 54, 509-517.
Powers HJ (2003) Riboflavin (vitamin B-2) and health. Am J Clin Nutr 77, 1352-1360.

Powers HJ \& Bates CJ (1987) Micronutrient deficiencies in the aetiology of anaemia in a rural area in The Gambia. Trans $R$ Soc Trop Med Hyg 81, 421-425.

Powers HJ, Bates CJ \& Lamb WH (1985) Haematological response to supplements of iron and riboflavin to pregnant and lactating women in rural Gambia. Hum Nutr Clin Nutr 39, 117-129.

Powers HJ, Bates CJ, Prentice AM, Lamb WH, Jepson M \& Bowman H (1983) The relative effectiveness of iron and iron with riboflavin in correcting a microcytic anaemia in men and children in rural Gambia. Hum Nutr Clin Nutr 37, 413-425.

Powers HJ, Wright AJ \& Fairweather-Tait SJ (1988) The effect of riboflavin deficiency in rats on the absorption and distribution of iron. Br J Nutr 59, 381-387.

Prasad AP, Lakshmi AV \& Bamji MS (1992) Interpretation of erythrocyte glutathione reductase activation test values for assessing riboflavin status. Eur J Clin Nutr 46, 753-758.

Reddy V (1998) Vitamin A and iron interactions. In http://ivacg. ilsi.org/publications/pubslist.cfm?publicationid=219. Washington: IVACG.

Sauberlich HE (1999) Vitamin B-2 (riboflavin). In Laboratory Tests for the Assessment of Nutritional Status, pp. 55-69. Boca Raton, FL: CRC Press.

Siekmann JH, Allen LH, Bwibo NO, Demment MW, Murphy SP \& Neumann CG (2003) Kenyan school children have multiple micronutrient deficiencies, but increased plasma vitamin B-12 is the only detectable micronutrient response to meat or milk supplementation. J Nutr 133, 3972S-3980S.

Sirivech S, Frieden E \& Osaki S (1974) The release of iron from horse spleen ferritin by reduced flavins. Biochem $J \mathbf{1 4 3}$, $311-315$

Staubli-Asobayire F () (2000) Development of a food fortification strategy to combat iron deficiency in the Ivory Coast. $\mathrm{PhD}$ Thesis, Swiss Federal Institute of Technology, Zurich.

Staubli Asobayire F, Adou P, Davidsson L, Cook JD \& Hurrell RF (2001) Prevalence of iron deficiency with and without concurrent anemia in population groups with high prevalences of malaria and other infections: a study in Cote d'Ivoire. Am J Clin Nutr 74, 776-782.

Suboticanec K, Stavljenic A, Schalch W \& Buzina R (1990) Effects of pyridoxine and riboflavin supplementation on physical fitness in young adolescents. Int J Vitam Nutr Res 60, 81-88.

Suprapto B, Widardo \& Suhanantyo (2002) Effect of low-dosage vitamin A and riboflavin on iron-folate supplementation in anaemic pregnant women. Asia Pac J Clin Nutr 11, 263-267.

Tanumihardjo SA, Permaesih D \& Muhilal (2004) Vitamin A status and hemoglobin concentrations are improved in Indonesian children with vitamin A and deworming interventions. Eur J Clin Nutr 58, 1223-1230.

Tillotson JA \& Baker EM (1972) An enzymatic measurement of the riboflavin status in man. Am J Clin Nutr 25, 425-431.

Toury J, Giorgi R, Favier JC \& Savina JF (1965) Aliments de l'Ouest Africain: Tables de Compositions. Dakar: Organisation de Coordination et de Coopération pour le lutte contre les grandes Endemies, Office de Recherches sur l'Alimentation et la Nutrition Africaines (ORANA).

Trape JF (1985) Rapid evaluation of malaria parasite density and standardization of thick smear examination for epidemiological investigations. Trans R Soc Trop Med Hyg 79, 181-184.

Traunmuller F, Ramharter M, Lagler H, Thalhammer F, Kremsner PG, Graninger W \& Winkler S (2003) Normal riboflavin status in malaria patients in Gabon. Am J Trop Med Hyg 68, 182-185.

Venkataswamy G (1967) Ocular manifestations of vitamin B-complex deficiency. Br J Ophthalmol 51, 749-754.

Wegmuller R, Camara F, Zimmermann MB, Adou P \& Hurrell RF (2006) Salt dual-fortified with iodine and micronized ground 
ferric pyrophosphate affects iron status but not hemoglobin in children in Cote d'Ivoire. J Nutr 136, 1814-1820.

WHO (1990) Diagnosis of Malaria. Geneva: PAHO Scientific Publication, No. 512 WHO.

WHO (1996) Indicators for Assessing Vitamin A Deficiency and their Application in Monitoring and Evaluating Intervention Programmes. Geneva: WHO.
WHO/UNICEF/UNU (2001) Iron Deficiency Anaemia. Assessment, Prevention and Control. A Guide for Programme Managers. Geneva: WHO.

Zimmermann MB, Molinari L, Staubli-Asobayire F, Hess SY, Chaouki N, Adou P \& Hurrell RF (2005) Serum transferrin receptor and zinc protoporphyrin as indicators of iron status in African children. Am J Clin Nutr 81, 615-623. 